\title{
PARENTERAL NUTRITION - ARE WE GIVING ENOUGH CALORIES AND PROTEINS?
}

\author{
Y. Singh, S. Chigullapalli, C. Reeder, C. Day \\ Department of Neonatal Medicine, Bradford Teaching Hospitals NHS Trust, Bradford, UK
}

Background: Parenteral nutrition (PN) is detrimental for the growth, development and survival of extremely premature babies. We have come a long way in providing nutrition to preterm babies in the initial few days but still practice varies in different units across the country and the world.

Aims and objectives: To determine whether we are able to give intended amount of parenteral nutrition and if not, how much is the calorie and protein loss?

Design and methods: A prospective audit done on random 65 episodes of parenteral nutrition provision and data was analysed to find whether we are giving intended amount of PN? Data was analysed to find out the protein and calories loss as compared to the existing unit standard.

Results: 65 days of parenteral nutrition was included in the audit. Gestational age varied from 23 week to term infants while birth weight range was 585 - 4175 grams. Mean of actual PN was $78 \%$ of intended with a median of $82 \%$ (IRQ range 68 - 92). Mean of feed was $15 \%$ of actual fluid given to babies. Average calorie loss was $20 \mathrm{Kcal} /$ day which comes out $14 \mathrm{Kcal} / \mathrm{Kg} /$ day. Median of protein loss was $1 \mathrm{gm} /$ day (IRQ range 0.3 $-1.2)$.

Conclusion: Despite following unit guideline in providing early PN we are failing to provide full amount of intended PN leading to significant calorie and protein loss. We need to look for further innovative ways to provide enough amount of PN, calories and proteins to infants needing PN therapy. 